CUAD. CONTAB. / BOGOTÁ, COLOMBIA, 16 (42): 661-687 / SEPTIEMBRE-DICIEMBRE 2015 / 661

\title{
Tableros de control como herramienta especializada: perspectiva desde la auditoría forense*
}

doi:10.11144/Javeriana.cc16-42.tche

\section{Mario Heimer Flórez-Guzmán}

Profesor investigador, Facultad de Contaduría Pública, Universidad Cooperativa de Colombia, sede Ibagué, Colombia. Integrante del grupo de investigación Planaudi. Director de la línea de investigación Contabilidad, Sociedad y Ambiente. Candidato a doctor en educación, Atlantic International University, AIU, Hawaii, Estados Unidos. Gerencia de instituciones, Especialista en física -física de partículas-, Universidad del Tolima. Matemático y físico, Universidad del Tolima. Estudios de maestría en alta gerencia, MBA, Universidad de Phoenix, Estados Unidos. Correo electrónico: mario.florez@campusucc.edu.co

\section{Ludivia Hernández-Aros}

Profesora investigadora, Facultad de Contaduría Pública, Universidad Cooperativa de Colombia, sede Ibagué,
Colombia. Integrante del grupo de investigación Planaudi. Estudiante de maestría en auditoría y gestión empresarial de la Universidad Internacional Iberoamericana, UNINI, Puerto Rico. Especialista en revisoría fiscal y control de gestión, Universidad Cooperativa de Colombia.

Correo electrónico: ludivia.hernandez@campusucc.edu.co

\section{Laura Constanza Gallego-Cossio}

Profesora investigadora, Facultad de Contaduría Pública, Universidad Cooperativa de Colombia, sede Ibagué, Colombia. Integrante del grupo de investigación Planaudi. Magíster en finanzas corporativas, Universidad Viña del Mar, Chile. Especialista en gestión empresarial, Universidad de Ibagué.

Correo electrónico: laura.gallego@campusucc.edu.co

\footnotetext{
* Artículo derivado de proyecto de investigación "Aseguramiento continúo de la información financiera mediante tableros de control" asociado al grupo PLANAUDI, adscrito a la Universidad Cooperativa de Colombia, sede Ibagué, del programa de Contaduría Pública, financiado por el Comité Nacional para el Desarrollo de la Investigación CONADI; proyecto en el cual se investigó en herramientas especializadas de análisis para el desarrollo del encargo en una auditoría como aporte al conocimiento global.
} 
Resumen El presente artículo muestra la incidencia que tiene el uso del tablero de control como herramienta especializada en el desarrollo de una auditoría forense. Este estudio se soporta desde la teoría del aseguramiento y de forma adyacente, la teoría del control. La literatura muestra que para este tipo de investigación, la metodología que más se ajusta es el estudio de caso con unidades incrustadas - varias unidades de análisis dentro del caso- planteado por Robert K. Yin (2005), en el cual las unidades se definieron como análisis de las etapas de una auditoría forense y aplicación del tablero de control al caso de estudio. Ahora bien, el resultado del proyecto de investigación pone en evidencia que el tablero de control - como herramienta especializada de análisis de datos-genera indicios sobre distorsiones, tendencias o resultados de indicadores que se salen de los parámetros establecidos en las fases de planeación, ejecución y dictamen de una auditoría forense.

Palabras clave tableros de control; herramienta especializada; auditoría forense; teoría del control: teoría del aseguramiento y riesgos

Códigos JEL M41, M42, M 48

\section{Control Boards as a Specialized Tool: Perspective from Forensic Auditing}

\footnotetext{
Abstract This article shows the incidence of the use of the control board as a specialized tool in the development of a forensic audit. This study is based on the theory of reinsurance and, concurrently, the theory of control. Literature shows that for this type of research the best methodological fit is the case study with embedded units -several analysis units within the case- as proposed by Robert K. Yin (2005), where units were defined as the analysis of the stages of a forensic audit and the application of the control board on the case study.

Now, the result of the research project shows that the control board, as a specialized data analysis tool, produces evidences of distortions, trends, or results from indicators
}

going off the parameters established in the planning, execution, and decision phases of a forensic audit.

Keywords Control boards; specialized tool; forensic audit; control theory; reinsurance and risk theory

\section{Painéis de controle como ferramenta especializada: perspectiva desde a auditoria forense}

Resumo O presente artigo mostra incidência que o uso do painel de controle tem como ferramenta especializada no desenvolvimento de uma auditoria forense. Este estudo é suportado desde a teoria de asseguração e, de forma adjacente, a teoria de controlo. A literatura mostra que para este tipo de pesquisa, a metodologia que mais se ajusta é o estudo de caso com unidades incrustadas - várias unidades de análise dentro do caso-colocado por Robert K. Yin (2005), no que as unidades foram definidas como análise dos estágios de uma auditoria forense e aplicação de painel de controlo ao caso de estudo.

Agora, o resultado do projeto de pesquisa põe em evidencia que o painel de controlo - como ferramenta especializada de análise de dados—cria indícios sobre distorções, tendências ou resultados de indicadores que estão fora dos parâmetros estabelecidos nos estágios de planejamento, execução e ditame de uma auditoria forense.

Palavras-chave painéis de controlo; ferramenta especializada; auditoria forense; teoria de controlo: teoria de asseguração e risco

\section{Introducción}

Los tableros de control permiten realizar un diagnóstico en tiempo real de todo lo que pasa en la organización y alertan sobre el nivel de cumplimiento - indicadores - de metas, para generar acciones de mejora. Los tableros de con- 
trol, según Anabel Montero-Posada y Margarita André-Ampuero (2013), proporcionan diferentes vistas de las métricas, reportes e indicadores, para cada uno de los niveles directivos.

Eduardo Montico-Riesco y Martín Velarde (2014) argumentan que en la construcción de un tablero de control se debe definir un conjunto de instrumentos o indicadores que permitan medir si las acciones que lleva adelante la compañía, están alineadas con las metas y objetivos organizacionales.

En este sentido, para el desarrollo de una auditoría, el tablero de control le permitirá al auditor estar a la vanguardia frente a los cambios presentes en los procesos organizacionales, pues tiene a su disposición una herramienta especializada de gestión, tecnológica y flexible. Estas herramientas ayudan a cumplir el ciclo propio de una auditoría - planeación, ejecución e informe-, organizar la información, direccionar el trabajo a seguir y soportarlo con evidencia amplia y suficiente para el informe final a presentar ante la organización.

En el encargo de una auditoría forense, el tablero de control alerta al auditor sobre situaciones anómalas, lo que le permite actuar en pro de la minimización en los riesgos de control y detección.

La investigación analiza la incidencia que tiene el uso del tablero de control como herramienta especializada en el desarrollo de una auditoría forense con elementos que identifican aspectos críticos, al tiempo que evidencian, valoran y detectan riesgos en la organización; por ello, se hace necesario la implementación de estrategias de seguimiento permanente.

Inicialmente, se identifica la normatividad internacional vigente para el ejercicio de una auditoría forense; a renglón seguido se describen las mejores prácticas de auditoría que utilicen las tecnologías de información y comunicación (TIC) como una de las herramientas especializadas que permiten el diseño de un modelo de tablero de control para evaluación de riesgos en una auditoría, desde la teoría del aseguramiento y la teoría del control.

Desde el aspecto metodológico, la investigación se soporta en el estudio de caso por medio de sus unidades de análisis que inicia con la incidencia de los tableros de control en la detección de debilidades que presenta el control interno desde la perspectiva administrativa y financiera.

De igual forma, la base de la información está en los documentos que evidencien el sistema de control interno de la organización objeto de estudio, con sus estados financieros y otros documentos como formularios para auditorías, entre otros.

Por último, se muestra el impacto que tiene en el encargo de una auditoría forense el uso del tablero de control como herramienta especializada, que permite disminuir los riesgos en su proceso de planeación y ejecución.

Con base en lo anterior surge la siguiente pregunta: ¿el tablero de control como herramienta incide positivamente en la disminución de riesgos en el proceso de auditoría forense?

\section{Herramientas especializadas para el análisis de datos en una auditoría}

La actividad empresarial en todo el mundo ha estado inmersa en el uso masivo de información; en la práctica, las organizaciones manejan 
grandes volúmenes de información que requieren herramientas sistémicas especializadas para organizarla y estructurarla, de tal manera que sea un puente entre lo que hay - la realidad empresarial- lo que se piensa hacer - lograr permanencia y posicionamiento de la empresa-y los medios para alcanzar el objetivo - el plan estratégico a seguir-. Esta situación evidentemente obliga a estar a la vanguardia de estas herramientas para lograr el acceso a la información en forma fácil, rápida, confiable, condensada y útil.

La estrecha relación entre las tecnologías de información y comunicación (TIC) con la organización da a entender la necesidad de su conocimiento, manejo y uso en todos los procesos internos y externos de la empresa. Fabio Enrique Gómez-Meneses (2014) identifica que la función esencial de las TIC es incrementar la capacidad de los trabajadores de creación, distribución y procesamiento de la información, que garantice el crecimiento económico de las organizaciones. Con base en lo anterior y teniendo en cuenta los grandes volúmenes de información que generan actualmente las organizaciones, el uso de las TIC se hace necesario para el manejo, procesamiento y análisis de esta, con una herramienta especiali- zada para el análisis de datos que permita la utilización de un tablero de control.

Actualmente es poco común el manejo manual de la información; en realidad, se toman los datos del sistema de información y se reorganizan de tal manera que se generen reportes de cómo está la organización y además, se pueda proyectar el grado de cumplimiento en los procesos y los niveles de riesgos propios de la actividad.

Con respecto a lo anterior, Eduardo Montico-Riesco y Martín Velarde (2014, p. 760) afirman que "las herramientas informáticas actuales permiten, además de visualizar el comportamiento de los indicadores en relación con el objetivo definido, incorporar diversos instrumentos para complementar esta rápida visión de la situación, como Scorecards y Dashboards".

Una de las labores más comprometidas con el uso de herramientas especializadas, es la auditoría - llámese interna o externa-, pues en ella reposa el mayor nivel de confianza en la evaluación de los sistemas de control, para que se informe en tiempo real sobre los riesgos que presenta la empresa y recomiende cómo minimizarlos. Algunas herramientas están presentes en el mercado y ayudan al desarrollo de la auditoría; entre ellas, tenemos:



Gráfico 1

Herramientas especializadas de auditoría

Fuente: elaboración propia 
Ahora bien, las anteriores herramientas focalizan sus funciones en la ayuda a la auditoría financiera. Por ello, desde otra mirada, se debe ver cómo el tablero de control va más allá de lo financiero, con la inclusión de lo administrativo y categorías que no son necesariamente financieras.

Eduardo Montico-Riesco y Martín Velarde (2014) definen el tablero de control, como un conjunto de instrumentos o indicadores que permitan medir si las acciones que lleva la compañía, están alineadas con las metas y objetivos. A partir de esta premisa, el tablero de control se considera una herramienta especializada de apoyo al auditor forense, para el desarrollo de un encargo.

\section{Tableros de control aplicados a las organizaciones}

El tablero de control nació como una herramienta gerencial con el objetivo básico de diagnosticar una situación y de efectuar un monitoreo permanente. Se define como el conjunto de indicadores cuyo seguimiento periódico permitirá contar con un mayor conocimiento sobre la situación de su empresa o sector, e identifica la salud de la empresa. Es un proceso de administración que, por medio de indicadores operativos, convierte información en valor agregado para la empresa y que se ajusta a entornos cambiantes.

María A. Cabeza, Edwin Corredor y María E. Cabeza (2007) afirman que en el tablero de control se configura información básica útil que permite diagnosticar una situación y realizar un seguimiento permanente, de tal manera que sus resultados se muestran a la alta gerencia para que conozca de antemano el estado de la organización y los resultados alcanzados. Esto significa que esta herramienta de control es muy importante para la gerencia, ya que evalúa constantemente los resultados obtenidos, producto de las decisiones que se toman.

Se parte de la premisa de que la organización debe tener herramientas de control que ayuden a salvaguardar sus activos. Nuno Miguel Delicado Teixeira (2014) argumenta que los instrumentos de control de gestión son importantes en la empresa y uno de ellos es el cuadro de mando integral, que ayuda al seguimiento adecuado de los resultados y determina en qué medida se cumplen los objetivos fijados.

Marco Antonio Machado-Rivera (2003) considera de mucha importancia la construcción de instrumentos, que tengan en cuenta las tendencias de la contabilidad de gestión, el uso de tableros de control y los adelantos en materia de tecnología informática; todo ello basado en los requerimientos del mundo empresarial moderno, que exige que se cumplan unos objetivos informativos, de planeación y control.

En el proceso de planeación, los tableros de control - al ser una herramienta que diagnostica y prevé los riesgos-fortalecen el plan estratégico de la organización y estandarizan criterios para empresas del mismo sector o tamaño en contraste con el proceso de auditoría contenido en la ISA 310 (International Standards on Auditing).

Por lo anterior, el auditor deberá tener $\mathrm{u}$ obtener un conocimiento del negocio suficiente para que sea posible plantear la estrategia a seguir y para que él pueda identificar y 
comprender los eventos, transacciones y prácticas que, a su juicio, tendrán un efecto importante sobre los estados financieros, en el examen o en el dictamen de auditoría; este conocimiento es también usado por el auditor al evaluar los riesgos inherentes y de control y al determinar la naturaleza, oportunidad y alcance de los procedimientos de auditoría.

Grandes empresas - como Hyperion (Nasdaq: HYSL) - presentan plataformas de inteligencia de negocios y ofrecen tableros de control interactivos que vinculan soluciones empresariales, a partir de los datos que se generan dentro y fuera de la compañía. Estas soluciones tecnológicas modernizan las actividades de la gerencia en cada una de las áreas y crean un nivel de confianza a los dueños de la compañía, pues reducen los costos, minimizan los riesgos e incrementan la productividad.

La administración de la información tiene la finalidad de evaluar la pertinencia y la eficacia de los procesos en la organización. El tablero de control favorece que la auditoría se alinee con los objetivos estratégicos, al evaluar el desempeño y los indicadores de gestión, los compromisos de la administración con los propietarios, el Estado y los stakeholders en general. Por lo anterior, los dueños de las empresas consideran otras mediciones no financieras como base para pedir a la administración la excelencia de la calidad en todos los sistemas y procesos de la organización, y mejorar su eficiencia y eficacia.

Hay diferentes tableros de control. Alberto Ballvé (2008) detalla los más comunes. Como ilustra el gráfico 2, cada uno de ellos aporta información suficiente para que la auditoría visualice los procesos realizados en la organización de una manera integral, de forma que el auditor posea información exacta y confiable para emitir su examen y generar el dictamen.

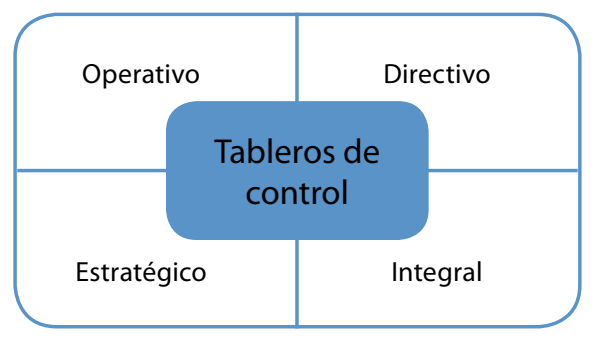

Gráfico 2

Clases de tablero de control

Fuente: elaboración propia

Por otro lado, la evaluación integral de los riesgos disminuye los errores por parte del auditor al no disponer del tiempo suficiente para la revisión de la totalidad de los estados financieros de la organización.

El auditor tendrá a su disposición una herramienta de control diario, la cual genera confianza en su labor y permite dinamizar la planeación del trabajo, a fin de cumplir todos los compromisos adquiridos en tiempo oportuno.

Para llevar a cabo el encargo de auditoría, el auditor realizará indagaciones ante la dirección y entre los auditores internos para determinar si tienen conocimiento, indicios o denuncia de fraude que afecten a la entidad, así como para conocer sus opiniones acerca del riesgo de fraude (Decreto 2420 de 2015, apartados A17 y A18).

De igual forma, el auditor evaluará si la información obtenida mediante otros procedi- 
mientos de valoración del riesgo y actividades relacionadas, indica la presencia de uno o varios factores de riesgo de fraude (Decreto 2420 de 2015, apartado A24); para ello, en el gráfico 3, se presentan algunos instrumentos que el auditor forense tiene a su disposición para evaluar los mecanismos de control.

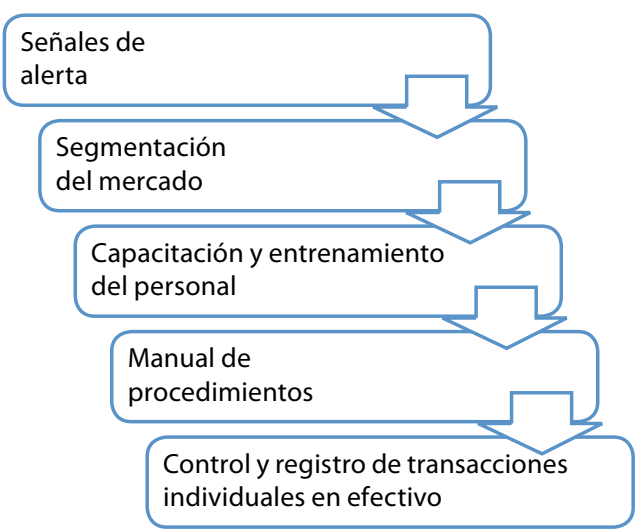

\section{Gráfico 3}

Instrumentos para la aplicación de los mecanismos de control

Fuente: elaboración propia

a. Las señales de alerta son el conjunto de indicadores que permiten identificar hechos, situaciones y eventos, de manera oportuna, a partir de lo cual se puede definir la existencia de una situación irregular que perjudica la entidad y se ha determinado como anormal. Rodrigo Estupiñán-García (2006) considera que las señales de alerta se pueden detectar cuando no hay una separación de funciones en los procesos o un solo individuo es el encargado de las transacciones; por otro lado, la eliminación de controles innecesarios, empleados sin vacaciones, liderazgo por miedo, conflictos de interés o compartir los passwords.

b. La segmentación del mercado que analiza si las operaciones realizadas por los clientes son o no sospechosas, para lo cual cada entidad de acuerdo a sus características propias debe establecer criterios relevantes para segmentar el mercado y de esta manera, identificar si los clientes realizan operaciones en ciertos segmentos superiores que no tienen justificación financiera.

c. La capacitación y entrenamiento del personal es una obligación de las organizaciones, las cuales deben diseñar y establecer programas de capacitación dirigidos a todos los funcionarios de la empresa, sobre las políticas, procedimientos y mecanismos e instrumentos de control adoptados por la entidad.

d. El manual de procedimientos describe los procesos que deben seguirse para ejecutar los mecanismos que adopte la entidad. Este manual es fundamental para la coordinación y evaluación administrativa, y contiene los requisitos que los clientes deben cumplir, los procedimientos de control interno y revisión, los documentos y registros que evidencien operaciones efectivas, entre otros.

e. El control y registro de transacciones individuales permite dejar constancia por escrito de las transacciones realizadas en efectivo que superen el monto establecido.

\section{Delitos financieros}

Ante el panorama de las organizaciones que son atacadas día a día por delitos financieros, se hace necesario actuar en consecuencia e implementar 
un plan de prevención contra esta clase de delitos (Albanese, 2012).

Luis Armando Leal-Rodríguez, Eduardo Rodríguez-Patiño y Raúl Eduardo GonzálezGarzón (2010) clasifican algunas modalidades de delitos las cuales se mencionan a continuación:

- Modalidades de fraudes con los estados financieros, en los que se tipifica todo tipo de registros sin soporte o manipulados desde el punto de vista contable.

- Modalidades en malversación de bienes, que pueden consumarse de varias maneras, incluyendo el desfalco de ingresos, el robo de activos, o cuando una entidad paga por bienes o servicios que no ha recibido.

- Modalidades de fraudes en sobornos, que se dan por la aceptación de regalos o dineros, por la influencia positiva en un contrato.

- Fraude en procesos de quiebras e insolvencias, que se presentan cuando no se cumplen los requisitos exigidos por la ley o se acomodan ciertas actuaciones de los liquidadores o los miembros del consejo administrador de los acuerdos concordatarios.

- Fraudes en impuestos, que regularmente son cometidos por los propietarios o administradores de las organizaciones, para favorecer sus intereses con el pago de menos impuestos.

Los anteriores fraudes, llevados ante un tribunal, se soportan en evidencias en las cuales interviene un perito, facultado por la organización o el juez, en cumplimiento de las dispo- siciones legales vigentes en Colombia que se presentan en la tabla 1.

\section{Auditoría forense}

A lo largo de su trayectoria como herramienta de prevención y de corrección de procesos de control organizacionales, la auditoría ha mostrado una evolución importante en los diferentes campos; hoy se cuenta con auditoría financiera, de sistemas, social, control interno, ambiental y auditoría forense, entre otras.

La auditoría forense tiene como finalidad la revisión de procesos para detectar e investigar actos ilícitos, lo cual hace necesario utilizar herramientas especializadas que permitan obtener datos suficientes y que de esta manera puedan ser analizados por el auditor. Lina María Ochoa-Bustamante, Julián Esteban Zamarra-Londoño y Jaime Alberto GuevaraSanabria (2011) argumentan que la auditoría forense es la encargada de la identificación del fraude, ejecutada por personas muy capacitadas en las diferentes modalidades de delitos organizacionales, en especial los económicos y financieros.

Braulio Rodríguez-Castro (2002) define la auditoría forense como:

"Forense" es un término moderno para localizar y presentar evidencia en forma efectiva y convincente. La ciencia forense es la aplicación de la ciencia a la ley; es el uso de los principios de la ciencia y la tecnología que se pueden aplicar para identificar, recuperar, reconstruir o analizar la evidencia durante una investigación de carácter civil o penal (p. 21). 
TABLEROS DE CONTROL COMO HERRAMIENTA ESPECIALIZADA / M. FLóREZ, L. HERNÁNDEZ, L. GALLeGo / 669

\begin{tabular}{|c|c|c|}
\hline & Ley & Artículos \\
\hline \multirow{36}{*}{ 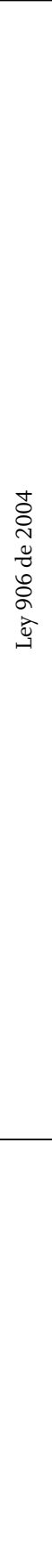 } & \multirow{8}{*}{ 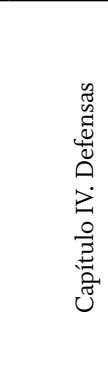 } & Artículo 239. Vigilancia y seguimiento de personas \\
\hline & & Artículo 267. Facultades de quien no es imputado \\
\hline & & Artículo 269. Contenido de la solicitud \\
\hline & & Artículo 270. Actuación del perito \\
\hline & & Artículo 271. Facultad de entrevistar \\
\hline & & Artículo 272. Obtención de declaración jurada \\
\hline & & Artículo 273. Criterios de valoración \\
\hline & & Artículo 274. Solicitud de prueba anticipada \\
\hline & \multirow{18}{*}{  } & Artículo 405. Procedencia \\
\hline & & Artículo 406. Prestación del servicio de peritos \\
\hline & & Artículo 407. Número de peritos \\
\hline & & Artículo 408. Quiénes pueden ser peritos \\
\hline & & Artículo 409. Quiénes no pueden ser nombrados \\
\hline & & Artículo 410. Obligatoriedad del cargo de perito \\
\hline & & Artículo 411. Impedimentos y recusaciones \\
\hline & & Artículo 412. Comparecencia de los peritos a la audiencia \\
\hline & & Artículo 413. Presentación de informes \\
\hline & & Artículo 414. Admisibilidad del informe y citación del perito \\
\hline & & Artículo 415. Base de la opinión pericial \\
\hline & & Artículo 416. Acceso a los elementos materiales \\
\hline & & Artículo 418. Instrucciones para contrainterrogar al perito \\
\hline & & Artículo 419. Perito impedido para concurrir \\
\hline & & Artículo 420. Apreciación de la prueba pericial \\
\hline & & Artículo 421. Limitación a las opiniones del perito sobre insanidad mental \\
\hline & & Artículo 422. Admisibilidad de publicaciones científicas y de prueba novel \\
\hline & & Artículo 423. Presentación de la evidencia demostrativa \\
\hline & \multirow{10}{*}{ 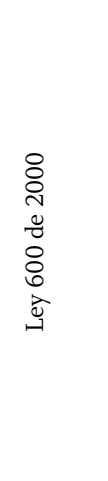 } & Artículo 249. Procedencia \\
\hline & & Artículo 250. Posesión de peritos no oficiales \\
\hline & & Artículo 251. Requisitos \\
\hline & & Artículo 252. Cuestionario \\
\hline & & Artículo 253. Término para rendir el dictamen \\
\hline & & Artículo 254. Contradicción del dictamen \\
\hline & & Artículo 255. Objeción del dictamen \\
\hline & & Artículo 256. Comparecencia de los peritos a la audiencia \\
\hline & & Artículo 257. Criterios para la apreciación del dictamen \\
\hline & & Artículo 258. Impedimentos y recusaciones \\
\hline
\end{tabular}




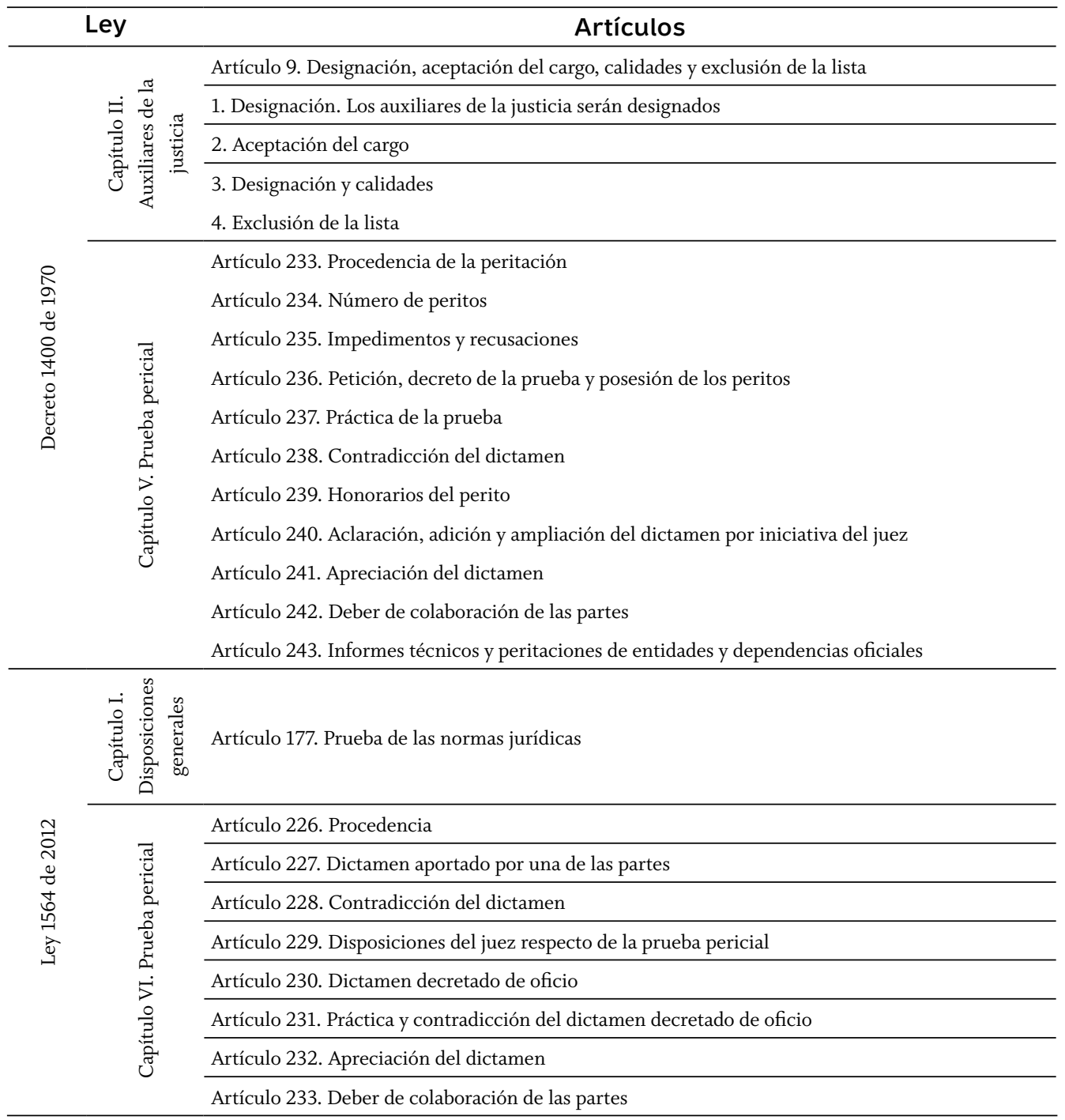

\section{Tabla 1}

Legislación del derecho probatorio de una auditoría forense aplicado a las pruebas periciales Fuente: elaboración propia

La auditoría forense recopila, evalúa y acumula evidencia, bajo procedimientos técnicos propios de la auditoría, con el fin de investigar indicios de fraude dentro de la organización. Al detectarlos, se hace necesario preparar un pro- grama que prevenga, controle, detecte y minimice los riesgos presentes.

La auditoría forense - con carácter de auditoría especializada- nace con el objetivo de descubrir e informar sobre fraudes y delitos en las 
organizaciones (Albanese, 2012). Una vez cometido el delito, en la mayoría de los casos, la contabilidad es considerada como la principal fuente de pruebas, ya que en ella reposa la evidencia del hecho que sucedió en la organización.

La auditoría forense como cualquier auditoría debe tener en cuenta los riesgos inherentes, de control y de detección, como lo explica Rodrigo Estupiñán-García (2006): a) riesgo inherente es la susceptibilidad del saldo de una cuenta o clase de transacciones, a una representación errónea que pudiera ser de importancia relativa, individualmente o cuando se agrega con representaciones erróneas en otras cuentas o clases de transacciones, asumiendo que no hubo controles internos relacionados, b) el riesgo de control es una representación errónea que pudiera ocurrir en el saldo de cuenta o clase de transacciones y que pudiera ser de importancia relativa individualmente o cuando se agrega con manifestaciones erróneas en otros saldos o clases, no sea prevenido o detectado y corregido con oportunidad por los sistemas de contabilidad y de control interno, y por último, c) el riesgo de detección se relaciona directamente con los procedimientos sustantivos del auditor.

La evaluación del auditor del riesgo de control y su evaluación del riesgo inherente influyen en la naturaleza, oportunidad y alcance de los procedimientos sustantivos para reducir el riesgo de detección y, por tanto, el riesgo en la auditoría, a un grado aceptablemente bajo.

El auditor forense debe ser una persona con experiencia en el campo del conocimiento, con formación objetiva, ética, independiente, honesta, inteligente, astuta, sagaz, planificadora, prudente y precavida; debe estar permanentemente en sospecha de todos y de todo, lo cual le permitirá ser capaz de identificar oportunamente cualquier indicio de fraude, bajo un trabajo guiado por su escepticismo profesional (Ocampo, Trejos-Buriticá \& Solarte-Martínez, 2010).

Por lo anterior, según Rodrigo EstupiñánGaitán (2006), la auditoría forense presenta algunas generalidades que la definen:

a. El término forense corresponde al latín forensis, que significa público; tiene su origen en el latín fórum que significa foro, plaza pública o de mercado en las antiguas ciudades romanas donde se trataban las asambleas públicas y los juicios.

b. En términos de contabilidad, la auditoría forense es una ciencia que reúne y presenta información financiera, contable, legal, administrativa y tributaria, ante los tribunales en una forma acertada, con los hallazgos de un indicio o un acto delictivo, contra los perpetradores de un crimen económico.

Evangelina Fontán-Tapia (2012) define la auditoría forense preventiva, AFP y la auditoría forense detectiva, AFD. La AFP se orienta a evitar fraudes en el futuro; proporciona evaluaciones o asesoramiento a diferentes organizaciones para disuadir, prevenir, detectar y proceder frente a diferentes tipos de fraude, con acciones como programas y controles antifraude, esquemas de alerta temprana de irregularidades y sistemas de administración de denuncias.

Por otro lado, la AFD se dirige hacia la existencia de fraudes mediante una profunda 


\section{2 / VOL. 16 / NO. 42 / SEPTIEMBRE-DICIEMBRE 2015}

investigación que establezca la cuantía del fraude, sus efectos directos e indirectos, su posible tipificación, sus presuntos autores, cómplices y encubridores.

\section{Metodología}

Dado que el objetivo de esta investigación es analizar la incidencia que tiene el uso del tablero de control en el desarrollo de una auditoría forense, se eligió como método de investigación el estudio de caso. Donna M. Mertens (2005) lo define como una investigación sobre un individuo, grupo, organización, comunidad o sociedad, el cual es visto y analizado como una entidad.

De igual forma, la U.S. General Accounting Office, GAO, en 1990, define que el estudio de caso constituye un método para aprender respecto a una instancia compleja, basado en un entendimiento comprehensivo de esta instancia como un "todo" y su contexto, mediante datos e información obtenidos por descripciones y análisis extensivos (Mertens, 2005); ahora bien, Harvard Business School lo considera un método y lo utiliza desde 1908 para evaluar unidades organizacionales (Hernández-Sampieri, FernándezCollado \& Baptista-Lucio 2006).

Así mismo, hay diferentes tipologías de estudio de caso; Robert E. Stake (1995) identifica tres diferentes tipos de estudios de caso: intrínsecos, instrumentales y colectivos. El propósito de los intrínsecos no es construir una teoría, sino que el caso mismo resulte de interés; los estudios de caso instrumentales se examinan para proveer de insumos de conocimiento algún tema o problema de investigación, refinar una teoría o aprender a trabajar con otros casos similares; por último, los colectivos sirven para construir un cuerpo teórico: sumar hallazgos, encontrar elementos comunes y diferencias, y acumular información.

Otra tipología significativa de estudio de caso es la planteada por Robert K. Yin (2005); en ella, encontramos la clasificación por número de casos y clase de unidad de análisis. Respecto al número de casos, los clasifica en un caso o varios casos; desde la clase de unidad de análisis, los tipifica en casos con unidad holística - todo el caso tomado como una sola unidad de análisis- $y$, casos con unidades incrustadas - varias unidades de análisis dentro del caso-.

Los tipos de casos resultantes de esta clasificación cruzada son diseños de investigación del método de caso o pueden ser concebidos como diseños específicos del estudio de caso (en concordancia con otros autores).

Específicamente y para dar cumplimiento al objetivo de la investigación, se realizará el estudio de un caso planteado por Robert K. Yin (2005) con unidades incrustadas; por lo anterior, las unidades de análisis dentro del caso son los tableros de control como herramienta especializada, que permite disminuir los riesgos en el proceso de planeación y ejecución de la auditoría forense.

Ahora bien, resulta pertinente hacer la precisión de que el principal insumo de información son los documentos que permitan evidenciar el sistema de control interno de la organización objeto de estudio, sus estados financieros y otros documentos como formularios para auditorías, entre otros.

La elección de estas fuentes de información facilita su triangulación y poder hacer la corre- 
lación entre las variables que se ajustan a la hipótesis central de la investigación: el tablero de control como herramienta incide positivamente en la disminución de riesgos en el proceso de auditoría forense.

Atendiendo - como se estipuló en el apartado anterior - a las diferentes etapas de una auditoría forense, y teniendo en cuenta las especificidades emitidas por la International Federation of Accountants, IFAC, y la Constitución colombiana, se procedió a hacer el tablero de control.

En la etapa de planeación de la auditoría forense, se tuvieron en cuenta los ítems planteados por Maricela Ramírez y Betty Johana Reina-Bohórquez (2013), para atender a su pertinencia; ahora bien, en cuanto a la ponderación del riesgo, se definen los rangos de calificación como:

- Existe (valor ponderado 100\% y color verde) cuando el auditor forense aplicó u obtuvo la evidencia de forma adecuada, amplia y suficiente.

- Existe parcialmente (valor ponderado $80 \%$ y color amarillo) cuando el auditor forense aplicó la prueba u obtuvo la evidencia con un grado de confianza entre el $80 \%$ y el 99\%.

- No existe (del valor ponderado con un nivel de confianza entre el 0\% y el 79\%); es necesario aclarar que los niveles de confianza fueron determinados a juicio de los investigadores.

\section{Resultados}

Para identificar la incidencia del uso de los tableros de control en una auditoría forense, se lleva a cabo el proceso de la auditoría teniendo en cuenta las normas internacionales de auditoría emitidas por la IFAC y las normas contempladas en la Constitución colombiana, para la detección de delitos financieros en este país.

Ahora bien, como se menciona anteriormente, la auditoría forense se ajusta a un proceso de auditoría tradicional, cuyo objetivo es la detección o prevención de delitos financieros. Maricela Ramírez y Betty Johana Reina-Bohórquez (2013) identifican las fases de la auditoría a partir de la planeación, el desarrollo del programa de auditoría forense, la comunicación de resultados y, por último, el seguimiento y monitoreo.

\section{Planeación}

Para el desarrollo de esta primera fase se hace prioritario conocer el negocio, con todo lo que esto implica, atendiendo a lo referente en la NIA 315, según la cual uno de los objetivos del auditor es identificar y valorar los riesgos de incorrección material, debida a fraude o error, tanto en los estados financieros como en las afirmaciones.

Para conseguir los objetivos y ejecutar las estrategias, la matriz de tableros de control concibe los resultados para orientar su trabajo y obtener evidencias. Y permite identificar los riesgos potenciales a partir de la NIA 320, entre los cuales están el de personal, los comerciales y financieros, el estructural, culturales y de control interno: que contiene el alcance, la estrategia, la materialidad, y controles en TIC.

Cada uno de estos riesgos se pondera para identificar las debilidades presentes de manera general en la organización frente a los riesgos en que puede incurrir. 
En caso de requerir habilidades especializadas para llevar a cabo la auditoría forense, quedará expuesta en esta fase como uso del trabajo de un experto. Por otro lado, en cuanto al proceso de convergencia con la Ley 1314 de 2009 y el decreto reglamentario 0302 de 2015, la normatividad colombiana considera que la planeación no es una fase discrecional, sino más bien un proceso continuo que es flexible ante los cambios o condiciones que se generen durante la auditoría.

\section{Desarrollo del programa de auditoría forense, tipificación del hecho}

Mediante el desarrollo de la planeación, se levantan las pruebas y evidencias necesarias para tipificar el fraude y se establece el grado de daño causado a la empresa; la labor que el auditor en su encargo desarrollará atiende la NIA 240, 315, 330. Así mismo, la NIA 520 incluye lo relacionado con los procedimientos analíticos.

En el proceso de recopilación de la evidencia, el auditor forense tendrá en cuenta lo dispuesto en materia probatoria, según la normatividad de la tabla 1. De igual forma, atenderá lo requerido por las Normas Internacionales de Auditoría en función del levantamiento de evidencia- en la NIA 500, 501, 505, 510, 540, 545, 550 y 560 y lo relacionado con la cadena de custodia (Ley 906 de 2004, artículos 254 y 266).

La evidencia a presentar en el desarrollo de la auditoría forense será suficiente y apropiada para presentar un dictamen cuya conclusión esté basada el uso de técnicas y herramientas propias del campo del conocimiento para recopilar pruebas físicas, pruebas testimoniales o prueba pericial, según sea el caso (Ley 902 de 2004, artículos 275, 284, 303, 404 y 434).

\section{Comunicación de resultados}

El auditor forense expresa sus resultados en un informe o dictamen. La NIA 700 muestra los lineamientos a tener en cuenta para los estados financieros de propósito general como el estado de situación financiera, el estado de resultados, el estado de cambio en el patrimonio y el estado de flujo de efectivo.

\section{Seguimiento y monitoreo}

Una vez practicada la auditoría forense, el seguimiento y el monitoreo son responsabilidades de la organización, ya que basada en el informe o dictamen, se establecerán controles - AFP — con el fin de minimizar los riesgos, para que en futuras ocasiones no vuelva a suceder un hecho delictivo.

\section{Descripción del caso de estudio}

\section{Antecedentes}

La empresa trabaja en el sector de la salud, está ubicada en una ciudad intermedia de Colombia y pertenece al sector privado con unos 20 años de existencia. Tras alertas percibidas por el gerente-entre las cuales están la incongruencia del estilo de vida de algunos empleados con respecto al salario devengado, los empleados que se negaban a disfrutar de las vacaciones, las jornadas de trabajo fuera del horario establecido sin reporte de horas extras para el respectivo cobro-, y otros tipos de alertas ya concernientes al funcionamiento de la empresa - como el nivel anormal del flujo de efectivo en comparación con el histórico que generaron problemas de liquidez, los problemas administrativos como la inconsistencia en la segregación de actividades, los 
débiles controles financieros y legales de la organización-generaron sospecha y la hipótesis del gerente en términos de que algunos empleados aprovecharan esta situación para su beneficio.

Con base en los aspectos anteriormente previstos por la gerencia de la organización, se decidió realizar una auditoría forense para detectar si se estaba incurriendo en fraudes financieros dentro de ella, por lo que se contrató una firma de auditoría reconocida en la ciudad.

\section{Procedimiento}

La firma inicialmente llevó a cabo la auditoría forense con técnicas y procedimientos tradicionales e hizo entrega de un informe preliminar que no fue de total satisfacción para la gerencia; posteriormente, la empresa solicitó a la firma un examen más detallado de lo sucedido en la organización; para esto, la firma decidió utilizar el tablero de control (TC) en el proceso de planeación, ejecución y entrega de informe de la auditoría forense.

En el desarrollo de la auditoría se exigieron documentos para el reconocimiento de la empresa; entre ellos estaban la copia de estatutos, la cual evidenció la constitución pero no las reformas a los estatutos; la copia de los permisos de funcionamiento y se solicitaron todas las licencias específicamente del sector salud sin que evidenciara plenamente la situación legal en todos los órdenes; se solicitaron algunos contratos a largo plazo de la compañía, pero no en su totalidad.

De igual forma se solicitaron algunos convenios y/o pactos colectivos de trabajo, pero el TC alerta que no se dio en su totalidad; adicionalmente, se requirieron los estados financieros del año inmediatamente anterior, lo que imposibilitaba determinar la trazabilidad del proceso financiero de la organización; además, se pidieron los informes de revisor fiscal y de gestión de los dos últimos años y se consideró importante solicitar los últimos cinco años, para analizar la situación de la organización desde el punto de vista histórico.

Como se evidencia en la tabla 2, el nivel de cumplimiento de la auditoría forense en el proceso de conocimiento general de la empresa era de 66,67\%; además, el TC mostró que el nivel de confianza estaba en amarillo y que la directriz marcó flecha inclinada hacia arriba, lo que implicaba que en la etapa de conocimiento general de la organización, estaba en nivel aceptable, pero que es mejor volver a repetir este proceso. Lo anterior debido a que esta actividad — conocimiento general de la organización- se considera prioritaria, pues sirve como base para la ejecución de la auditoría, lo que permite al auditor lograr un adecuado entendimiento de la organización respecto a los tipos de transacciones, las cuentas de balance y las revelaciones que espera que contengan los estados financieros sujetos a examen (NIA, 315).

El tablero de control cuenta con una lista desplegable, lo que condujo al auditor a verificar plenamente todas las variables que debía tener en cuenta en el proceso de auditoría - para este caso, conocimiento general de la organización-. Una vez se hace clic, se genera una lista desplegable del tipo de empresa y una lista de ítems a tener en cuenta por el auditor en el proceso de auditoría. 
676 / VOL. 16 / NO. 42 / SEPTIEMBRE-DICIEMBRE 2015






TABLEROS DE CONTROL COMO HERRAMIENTA ESPECIALIZADA / M. FLóREZ, L. HERNÁNDEZ, L. GALLeGo / 677

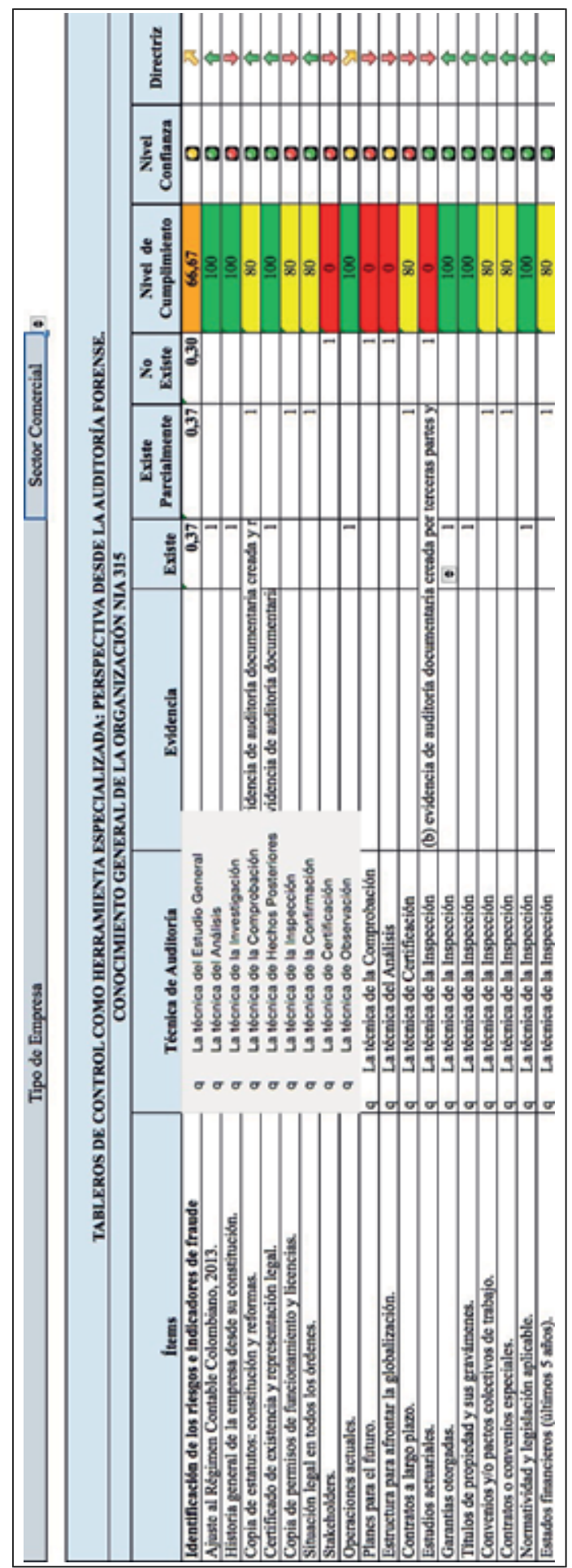

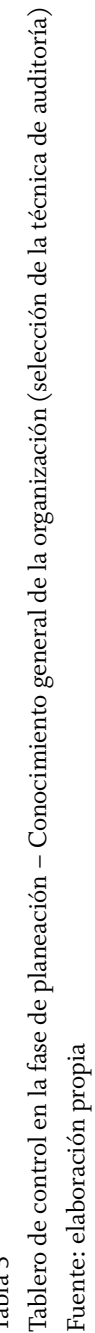


En la columna siguiente se despliega la técnica de auditoría a usar, con la posibilidad de elegir adecuadamente, con opciones de técnica de inspección, certificación, observación, análisis, entre otros; en esta columna - técnica de auditoría-, el auditor tendrá la posibilidad de verificar el valor de confianza que hay entre la técnica que ha elegido y la que debería elegir correctamente, lo que le permite determinar si está eligiendo bien la técnica y esto se muestra en la columna denominada nivel de confianza. El ícono - un semáforo-muestra verde cuando se ha elegido la técnica correcta, amarillo cuando se ha elegido una técnica que, aunque no es la ideal, también puede ser considerada para esta actividad, y rojo cuando definitivamente la técnica que ha elegido no es congruente con el tipo de ítem que se desea evaluar.

Una vez se ha elegido la técnica, se despliega la columna evidencia, la cual — como se muestra en la tabla 4- deja ver las categorías para el tipo de evidencia que se requiera dependiendo de la técnica que se ha elegido; a) evidencia de auditoría documentaria creada y retenida por terceras partes, b) evidencia de auditoría documentaria creada por terceras partes y retenida por la entidad, y c) evidencia de auditoría documentaria creada y retenida por la entidad; además, el tablero de control (TC) permite evaluar si la categoría de la evidencia es adecuada o no, pues alerta al auditor mediante el cambio de color de semáforo que afecta el nivel de confianza.

Seguidamente, se evaluó el nivel de cumplimiento de la evidencia, con los ítems existe, existe parcialmente, no existe, a los cuales se les ha dado un valor ponderado de 100\%, 80\% y
$0 \%$, respectivamente. Lo anterior se refleja en la columna nivel de cumplimiento con el resultado: rojo para un cumplimiento menor al 50\%, amarillo para un cumplimiento entre el 51\% y el $90 \%$ y verde para un cumplimiento mayor al $91 \%$.

Ahora bien, la última columna del TC - llamada directriz- muestra si después de haber cumplido todos los pasos de la auditoría, esta debe ser revisada de nuevo o simplemente genera un grado de confianza positivo - para el auditor-y puede continuar con el proceso; la flecha verde corresponde a que el proceso está correcto o que después de analizadas todas las variables, el ponderado está por encima de 90\%; la amarilla ascendente quiere decir que debe revisarse de nuevo o no; la flecha amarilla descendente indica que aunque el auditor puede no repetir el proceso, es mejor que lo haga y la flecha roja indica que el proceso debe hacerse de nuevo.

En la tabla 5 se muestra la identificación de riesgos de personal; los auditores en la fase inicial solicitaron los siguientes documentos: indicios de actos ilegales - llamados de atención-, hojas de vida de los empleados para determinar la frecuencia con que se habían hecho estos; se comparó también el salario con el estilo de vida, el cual fue una de las variables que generó sospecha inicialmente por parte de la gerencia; también se tuvieron en cuenta las vacaciones no tomadas por los empleados que presuntamente estuvieran incurriendo en el delito.

De igual forma, se solicitaron los estados financieros de la empresa para determinar la materialidad de las cuentas y el entendimiento del 
TABLEROS DE CONTROL COMO HERRAMIENTA ESPECIALIZADA / M. FLóREZ, L. HERNÁNDEZ, L. GALleGo / 679

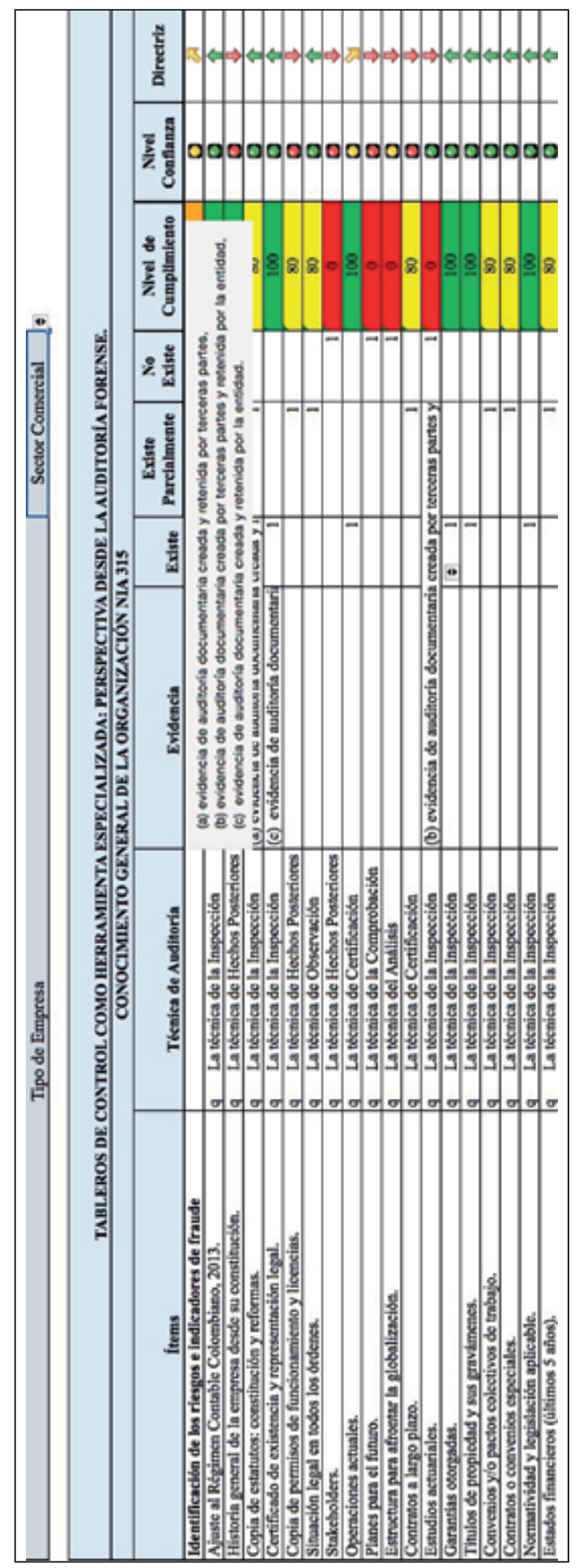

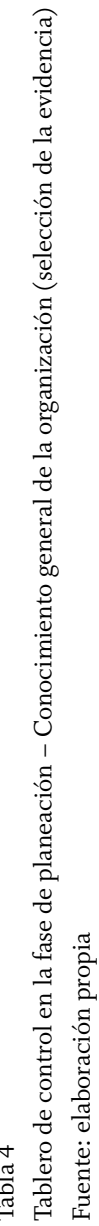


680 / VOL. 16 / NO. 42 / SEPTIEMBRE-DICIEMBRE 2015

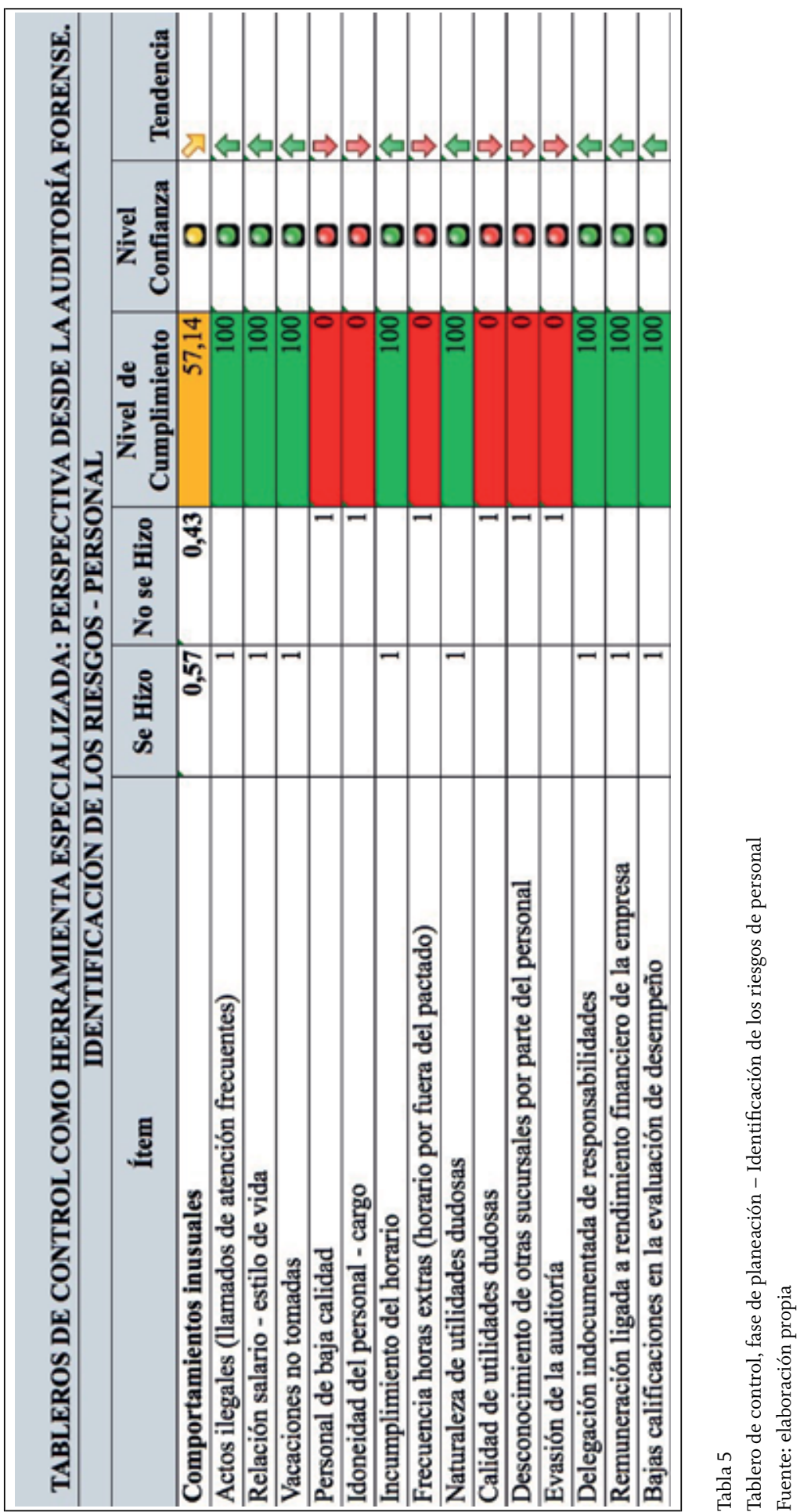


estado financiero respecto al objeto social de la organización; los auditores también evidenciaron la falta de un manual de funciones dentro de la organización, lo cual permitió que los funcionarios realizaran diversas actividades que en ocasiones pueden tener un alto riesgo en el control.

En la tabla 5, se evidencia claramente que hay aspectos importantes a tener en cuenta en la fase de planeación y que pueden ser ponderados para determinar qué tan confiable es la evidencia que se está mostrando en esta etapa de la auditoría forense; para este caso, la evaluación de riesgos en el TC arroja un nivel de cumplimiento de $57,14 \%$, la directriz muestra flecha amarilla descendente, lo que se implica que es un bajo nivel de confianza y por lo tanto, se debe ajustar el examen conforme al cumplimiento a la NIA; este aspecto se considera importante, porque genera indicios de comportamientos inusuales del (de los) empleado(s) que tienen acceso a la información y que participan directa o indirectamente de los actos delictivos en la organización.

Después de aplicar el TC, el nivel de cumplimiento en la identificación de riesgos aumenta del 57,14\% al 99,00\%, lo que constituye una variación importante, teniendo en cuenta que se hizo el ajuste a pedido de los auditores: pruebas que determinen si el personal era idóneo para la actividad que ejercían, el itinerario de trabajo fuera del horario establecido - horas extra no reportadas para cobro-para lo cual el auditor, mediante el análisis de los estados financieros, verificó y reportó los indicios de la evasión, para generar elementos de prueba amplia y suficiente en el momento de necesitarse a instancias mayores — tribunal judicial-.
En esta sección, se muestra que la evaluación de control interno realizada por el auditor se encuentra en un nivel de confianza de $100 \%$, lo que evidencia que cumple la normatividad nacional e internacional exigida; lo anterior, pues el proceso de auditoría de evaluación del control interno es ampliamente conocido por la mayoría de los auditores. Esto indica que el auditor contó con elementos de control suficientes, para identificar y evaluar la presencia de riesgos que generaron el fraude en la organización.

Una vez analizados todos los ítems que se requieren para el desarrollo de la auditoría forense y en cumplimiento de las NIA, la Ley 906 en los artículos del Código de Procedimiento Penal: 275 al 285 (prueba física); 303 al 404 (prueba testimonial); 404 al 434 (prueba pericial), se evidencia que para este caso, el nivel de confianza arrojado por el tablero de control es de $61,17 \%$. Ahora bien, este valor es considerado por los auditores como bajo, por lo que se puede concluir que no hay un buen ejercicio del auditor, dictamen que será poco objetivo y que probablemente no aportará prueba amplia y suficiente en instancias judiciales.

Con base en lo anterior, se evidencia en el TC, que - en este encargo específicamente- la cadena de custodia contemplada en la Ley 906 de 2004 (Art. 254-266 CPP) está en riesgo; este aspecto es fundamental en el proceso pericial, pues sirve para demostrar la autenticidad de los elementos materiales probatorios y la evidencia física; este proceso garantiza la veracidad de la información recolectada y muestra un problema en la autenticidad de la prueba (Leal-Rodríguez, Rodríguez-Patiño \& GonzálezGarzón, 2010). 
682 / VOL. 16/ NO. 42 / SEPTIEMBRE-DICIEMBRE 2015

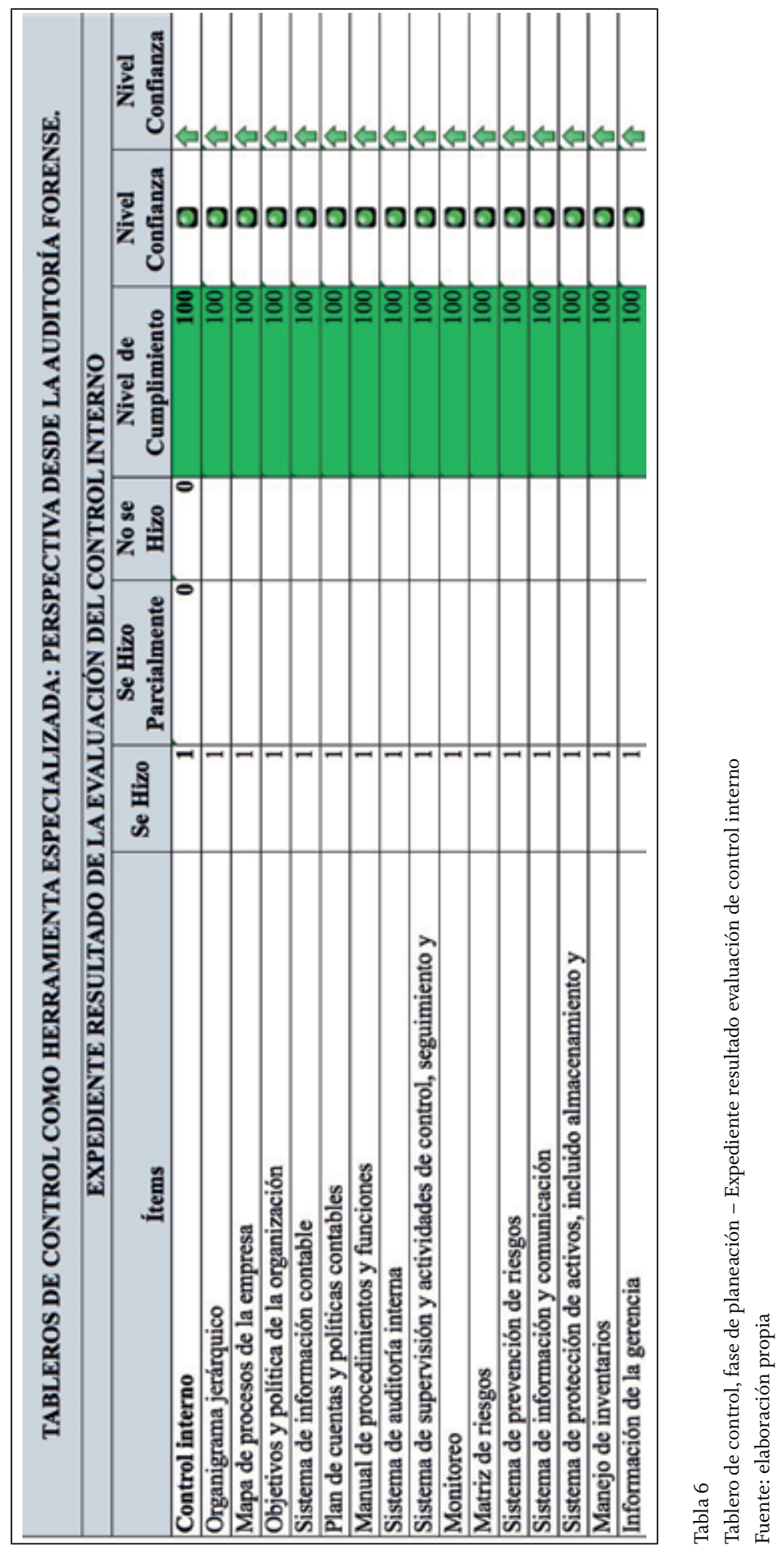


TABLEROS DE CONTROL COMO HeRRAMienta ESPECIALIZADA / M. FLóREZ, L. HERNÁNDEZ, L. GALleGo / 683

\begin{tabular}{|c|c|c|c|c|c|c|}
\hline \multicolumn{2}{|c|}{ Tipode Empresa } & \multicolumn{5}{|c|}{ Sector Solidario } \\
\hline \multicolumn{7}{|c|}{ TABLEROS DE CONTROL. COMO HERRAMIIENTA ESPECLALIZADA: PERSPECTIVA DESDE LAALDITORIA FOREXSE. } \\
\hline \multirow{2}{*}{ Alerta } & \multicolumn{4}{|c|}{ DESARROLLO DE LAALDITORIA } & \multicolumn{2}{|c|}{61,17627059} \\
\hline & 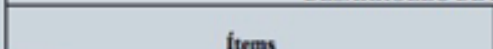 & Se Hiso & Se Hilwo & No se & No & $\begin{array}{c}\text { Nivel } \\
\text { Confianga }\end{array}$ \\
\hline & Dincro & & & & & 0 \\
\hline 100 & Bicens & & & & & 总 \\
\hline &  & & & & & 西 \\
\hline 100 & Elementos materiales descubienos & & & & & D \\
\hline 100 & Inspoceclón material & & & & & 员 \\
\hline 100 & Reqistro material & & & & & 吕 \\
\hline & Conseo electrónico & & & & & D \\
\hline & Revisidn facturas telefonicas & & & & & 量 \\
\hline T & Revisión mensajes de tectoo & & & & & 它 \\
\hline & Telequamas & & & & & D \\
\hline e & Telex & & & & & D \\
\hline  & Teleffax & & & & & D \\
\hline 80 & Mensajes de deos duplicados & & & & & D \\
\hline & Presunción en recepción de mensajes de datos & & & & & D \\
\hline 100 & Uso de firmas digitales en festurns & & & & & D \\
\hline 100 & Uso de firmas digitales en cheques & & & & & D \\
\hline 100 & Uso de firmas digitales en oeros documerntos financietos & & & & & D \\
\hline 80 & Emision de centifcados con firmas digitales & & & & & D \\
\hline 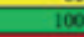 & Se verifico la lezalidad de la prueba & & & & & 台 \\
\hline $\bar{c}$ & Se iócrnifico la trazabilidad de la prueba & & & & & D \\
\hline 100 & Se verificó la auterticidad de la procta & & & & & D \\
\hline & 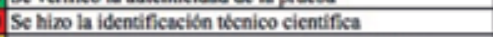 & & & & & 吕 \\
\hline & Elemento material probetorio y evidencia fisica & & & & & \\
\hline 80 & recogidos por agente encubierto o por agente infilitrado & & & & & Q \\
\hline 100 & $\begin{array}{l}\text { Elementemo material probatorio y evidencia fisica } \\
\text { recopidos en desarrollo de entroga vigilads }\end{array}$ & 1 & & & & a \\
\hline & $\begin{array}{l}\text { Elementoto material probatorio y evidencia fisica } \\
\text { remitidos del extranier }\end{array}$ & & & & & 西 \\
\hline 100 & Imterrogatorio a indiciodo & & & & & D \\
\hline 100 & Aospeación por el impuraso & & & & & D \\
\hline 80 & Procba anticlpada & & & & & D \\
\hline & Conservación de la prueba amicicipada & & & & & D \\
\hline 100 & Búsqueda selectiva en bases de dators & & & & & D \\
\hline 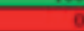 & Reqla pentral & & & & & D \\
\hline & Examen grafotecenico personal & & & & & 量 \\
\hline 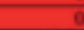 & Examen grnfortenico en miguina & & & & & D \\
\hline 100 & Todo se hizo en presencia del defensor imputado & & & & & D \\
\hline 100 & Reconocimiento por videes y fotcernfias & & & & & 旨 \\
\hline r & Inicio de la cadena de custodia & & & & & D \\
\hline a & Trasledo de contenedor & & & & & 嚍 \\
\hline & Traspaso de coentenedor & & & & & D \\
\hline 100 & Actuasción del perito. & & & & & D \\
\hline 100 & Responsabilidad de cada custodio & & & & & D \\
\hline 100 & Remanentes & & & & & 照 \\
\hline 100 & Acta Examen pecvio al recilbo & & & & & 总 \\
\hline & Se verified la ldentificasión del funcionario de embalaje & & & & & D \\
\hline e & Se certifico la cadena de custodia & & & & & 台 \\
\hline 100 & Se verificó el acta de entrega de elememos custodiados & & & & & D \\
\hline & $\Lambda$ cta de verifeación de comeneodores de informacion & & & & & D \\
\hline 100 & $\begin{array}{l}\text { Verificación de que la solicioud reìne las mencioendas } \\
\text { condiciones necesarias }\end{array}$ & & & & & a \\
\hline 100 & $\begin{array}{l}\text { Acta de informe pericial en el que se incluye los } \\
\text { letementos de prueba }\end{array}$ & & & & & 西 \\
\hline & $\begin{array}{l}\text { Entrevistas presentadas por el imputado corresponden a } \\
\text { las acepeadas por criminalistica }\end{array}$ & & & & & \\
\hline 100 & & & & & & o \\
\hline$m$ & Se tiene recibo de la entrega del informe pericial al & & & & & . \\
\hline$\frac{100}{100}$ & Obecencition de declaración Jurada & & & & & 岩 \\
\hline
\end{tabular}

Tabla 7

Tablero de control, fase desarrollo de la auditoría

Fuente: elaboración propia 
Ahora bien, después de implementar el tablero de control, se aumenta el nivel de confianza del $61,2 \%$ al $99,0 \%$, lo que se considera bastante significativo, y de esta forma se puede asegurar que la etapa de ejecución de la auditoría forense cuenta con los elementos necesarios para el levantamiento de prueba amplia y suficiente del presunto delito financiero que se cometió en la organización.

\section{Conclusiones}

La investigación busca mostrar el impacto que tiene en el encargo de una auditoría forense con el uso del tablero de control como herramienta especializada, lo cual — se evidencia en el desarrollo del documento- logró disminuir los riesgos en su proceso de planeación y ejecución, por lo que se concluye que el TC efectivamente disminuye los riesgos en el proceso de una auditoría forense, pues permite hacer un chequeo detallado de los pasos que debe tener una auditoría forense, las técnicas que deben utilizarse, las categorías y tipos de evidencia, y el proceso contemplado en el Código de Procedimiento Penal colombiano en lo referente a la cadena de custodia de la prueba, con un informe que contenga un alto grado de confianza, tanto para quien contrata la auditoría, como para que sea tenido en cuenta en un proceso civil o penal.

Con base en lo anterior, al haber sido ejercida la auditoría forense - en este caso de estudio específico-por un contador público, algunos de los ítems que son criminalísticos no fueron tenidos en cuenta por este; de igual forma, el análisis muestra que la auditoría forense que se realizó tuvo debilidades en la etapa de pla- neación frente al conocimiento general de la empresa y en contraste con la evaluación del control interno se mostró una fortaleza; también se identificó una debilidad en la custodia de las pruebas, lo que se considera bastante comprometedor sobre todo en su veracidad y específicamente en una auditoría forense.

El tablero de control como herramienta especializada para el análisis de datos genera indicios sobre distorsiones, tendencias o resultados de indicadores que se salen de los parámetros establecidos en las fases de planeación, ejecución y dictamen de una auditoría forense, lo cual se evidenció en este caso de estudio con la identificación de otros elementos para obtener un nivel de confianza cercano al 100\% en el desarrollo de este encargo, como lo muestran las tablas analizadas.

El uso de tablero de control en el encargo de la auditoría forense aumenta el nivel de cumplimiento y de confianza del 66,67\% al 99,00\% en referencia al conocimiento general de la organización; del 57,14\% al 100,00\% en la identificación de riesgo de fraude en el personal; y de un 61,12\% al 99,00\% en la etapa de ejecución de una auditoría, lo que muestra que su uso está fuertemente relacionado con la legalidad, pertinencia, autenticidad y aducción del mismo, como se evidencia en los tableros de control: TC 2 conocimiento general de la organización NIA 315, TC 3 identificación de los riesgos, TC 4 expediente resultado de la evaluación del control interno y TC 5 desarrollo de la auditoría.

Finalmente, el tablero de control reviste gran importancia en una auditoría forense, pues su utilización propende por la disminución de riesgos en su encargo, en cuanto per- 
mite identificar cada una de las variables en las fases del proceso de auditoría de forma sistemática, para mitigar los riesgos inherentes a esta; por lo anteriormente expuesto se decide aceptar la hipótesis inicialmente planteada "el tablero de control como herramienta incide positivamente en la disminución de riesgos en el proceso de auditoría forense"; lo anterior por su impacto en el nivel de confianza en cada una de las fases de la auditoría.

\section{Referencias}

Albanese, Diana Ester (2012). Análisis y evaluación de riesgos: aplicación de una matriz de riesgo en el marco de un plan de prevención contra el lavado de activos. Base, Revista de Administração e Contabilidade da UNISINOS, 206-215. Disponible en: http:// revistas.unisinos.br/index.php/base/article/ view/base.2012.93.01/1091

Ballvé, Alberto M. (2008). Tablero de control. Organizando información para crear valor. Textos y casos de empresas. Buenos Aires: Macchi.

Cabeza, María A.; Corredor, Edwin \& Cabeza, María E. (2007). Elaboración de un tablero de control para la Compañía Anónima de Administración y Fomento Eléctrico (CADAFE). Revista Venezolana de Análisis de Coyuntura, Universidad Central de Venezuela, 13 (2), 333-348. Disponible en: http://www. redalyc.org/articulo.oa?id=36413217

Colombia (1991). Constitución Política. Gaceta Constitucional, 116, 20 de julio de 1991. Versión corregida disponible en: http:// www.secretariasenado.gov.co/senado/ basedoc/constitucion_politica_1991.html
Colombia (2012). Decreto 1400 de 1970, por el cual se expide el Código de Procedimiento Civil. Diario Oficial, 33.150, 21 de septiembre de 1970. Disponible en: http://www.secretariasenado.gov.co/ senado/basedoc/codigo_procedimiento_ civil.html

Colombia (2015). Decreto 2420 de 2015, por medio del cual se expide el Decreto Único Reglamentario de las Normas de Contabilidad, de Información Financiera y de Aseguramiento de la Información y se dictan otras disposiciones. Diario Oficial, 49.735, 23 de diciembre de 2015. Disponible en: http://wp.presidencia. gov.co/sitios/normativa/decretos/2015/ Decretos2015/DECRETO\%202420\%20 DEL\%2014\%20DE\%20DICIEMBRE\%20 DE\%202015\%20-\%20copia.pdf Colombia (2015). Decreto reglamentario 0302 de 2015, por el cual se reglamenta la Ley1314 de 2009 sobre el marco técnico normativo para las normas de aseguramiento de la información. Diario Oficial, 49.431, 20 de febrero de 2015. Disponible en: http://www. comunidadcontable.com/BancoMedios/ Documentos\%20PDF/d-030215(mincomercio).pdf

Colombia (1990). Ley 43 de 1990, por la cual se adiciona la Ley 145 de 1960, reglamentaria de la profesión de contador público y se dictan otras disposiciones. Diario Oficial, 39.602, 13 de diciembre de 1990. Bogotá, Colombia. Disponible en:http://www. mineducacion.gov.co/1621/articles-104547_ archivo_pdf.pdf 
Colombia (2000). Ley 600 de 2000, por la cual se expide el Código de Procedimiento Penal. Diario Oficial, 44.097, 24 de julio de 2000. Disponible en: http://www. secretariasenado.gov.co/senado/basedoc/ ley_0600_2000.html

Colombia (2004). Ley 906 de 2004, por la cual se expide el Código de Procedimiento Penal (corregida de conformidad con el Decreto 2770 de 2004). Diario Oficial, 45.658, 1 de septiembre de 2004. Disponible en: http:// www.secretariasenado.gov.co/senado/basedoc/ley_0906_2004.html

Colombia (2009). Ley 1314 de 2009, por la cual se regulan los principios y normas de contabilidad e información financiera y de aseguramiento de información aceptados en Colombia, se señalan las autoridades competentes, el procedimiento para su expedición y se determinan las entidades responsables de vigilar su cumplimiento. Diario Oficial, 47.409, 13 de julio de 2009. Disponible en: http://www. secretariasenado.gov.co/senado/basedoc/ ley_1314_2009.html

Colombia (2012). Ley 1564 de 2012, por medio de la cual se expide el Código General del Proceso y se dictan otras disposiciones. Diario Oficial, 48.489, 12 de julio de 2012. Disponible en: http://www. secretariasenado.gov.co/senado/basedoc/ ley_1564_2012.html

Estupiñán-Gaitán, Rodrigo (2006). Control interno $y$ fraudes con base en los ciclos transaccionales: análisis de informe COSO I y II. Bogotá D. C.: Ecoe Ediciones.
Fontán-Tapia, Evangelina (2012). El impacto de la auditoría forense como técnica de prevención, detección y control de fraude. Disponible en: http://www.ideaf.org/archivos/ideaf_impacto_af_prev_det_cont_fraude.pdf

Gómez-Meneses, Fabio Enrique (2014). Competencia digital en la auditoría. Soporte o carga en el ejercicio profesional de los auditores. Cuadernos de Contabilidad, 15 (37), 135-151. Disponible en: http:// cuadernosdecontabilidad.javeriana.edu.co/ vol15_n_37/vol15_37_5.pdf

Hernández-Sampieri, Roberto; Fernández-Collado, Carlos \& Baptista-Lucio, Pilar (2006). Metodología de la investigación, Capítulo IV, Estudio de caso, 50-75. $4^{\mathrm{a}}$ ed. México: McGrawHill. Disponible en: http://novella.mhhe.com/ sites/dl/free/000001251x/1058642/CAPITULO04.pdf

Leal-Rodríguez, Luis Armando; RodríguezPatiño, Eduardo \& González-Garzón, Raúl Eduardo (2010). Auditoría forense: los procedimientos del contador público en la investigación del fraude corporativo. Gestión \& Sociedad, 3 (2), 141-160. Disponible en: http://revistas.lasalle.edu.co/index.php/gs/ article/viewFile/934/841

Machado-Rivera, Marco Antonio (2003). De la contabilidad de costos a los tableros de control. Contaduría Universidad de Antioquia, 42, 129-158. Disponible en: https://aprendeenlinea.udea.edu.co/revistas/index.php/ cont/article/viewFile/25656/21179

Mertens, Donna M. (2005). Research and Evaluation in Education and Psychology. Integrating Diversity with Quantitative, Qualitative, and Mixed Methods. $2^{\text {nd }}$ ed. Thousand Oaks: Sage. 
Montero-Posada, Anabel \& André-Ampuero, Margarita (2013). Herramienta de soporte a un sistema de métricas e indicadores para la gestión de proyectos. Revista Cubana de Ciencias Informáticas, 7 (2), 127-144. Disponible en: http://scielo.sld. cu/scielo.php?script $=$ sci_arttext\&pid $=$ S2227-18992013000200004

Montico-Riesco, Eduardo \& Velarde, Martín (2014). Formulación de un tablero de comando para el análisis de la productividad y la gestión competitiva en el sector salud. Cuadernos de Contabilidad, 15 (39), 745-762. Disponible en: http://revistas.javeriana.edu.co/index.php/cuacont/article/ view/12872/10326

Ocampo-S., Carlos Alberto; Trejos-Buriticá, Ómar Iván \& Solarte-Martínez, Guillermo Roberto (2010). Las técnicas forenses y la auditoría. Scientia et Technica, 16 (45), 108113. Disponible en: http://www.redalyc.org/ pdf/849/84917249019.pdf

Ochoa-Bustamante, Lina María; Zamarra-Londoño, Julián Esteban \& Guevara-Sanabria, Jaime Alberto (2011). ¿Cuál ha sido la responsabilidad de la auditoría en los escándalos financieros? Contaduría Universidad de Antioquia, 58-59, 117-145. Disponible en: http://aprendeenlinea.udea.edu.co/revistas/ index.php/cont/article/view/14632

Ramírez, Maricela \& Reina-Bohórquez, Betty Johanna (2013). Metodología y desarrollo de la auditoría forense en la detección del fraude. Cuadernos de Administración,
29 (50), 186-195. Disponible en: http:// cuadernosdeadministracion.univalle.edu. co/index.php/cuadernosadmin/article/ view/1947/2349

Rodríguez-Castro, Braulio (2002). Una aproximación a la auditoría forense. Bogotá: Pontificia Universidad Javeriana, PUJ. Disponible en: http:/www.ideaf.org/archivos/ auditoria\%20forense\%20articulos.pdf Stake, Robert E. (1995). The Art of Case Study Research. Thousand Oaks, California: Sage. Teixeira, Nuno Miguel Delicado (2014). La contribución de los sistemas de control de gestión para el éxito empresarial. Cuadernos de Contabilidad, 15 (39), 853-881. Disponible en: http://revistas.javeriana. edu.co/index.php/cuacont/article/download/12877/10331

Yin, Robert K. (2005). Estudo de caso: planejamento e métodos. 3 ed. Porto Alegre: Bookman.

- Fecha de recepción: 25 de junio de 2015

- Fecha de aceptación: 24 de agosto de 2015

- Disponible en línea: 15 de mayo de 2016

\section{Para citar este artículo}

Flórez-Guzmán, M. H.; Hernández-Aros, L. \& Gallego-Cossio, L. C. (2015). Tableros de control como herramienta especializada: perspectiva desde la auditoría forense. Cuadernos de Contabilidad, 16(42), 661-687. http://dx.doi.org/10.11144/Javeriana.cc16-42.tche 
